\title{
LA AXIOLOGÍA JURÍDICA Y LA SELECCIÓN DE MÉTODOS DE INTERPRETACIÓN
}

Julio C. Cueto Rúa

Universidad de Buenos Aires (Argentina)

\section{Introducción}

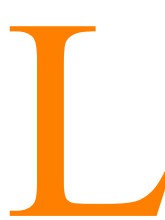

os métodos de interpretación del Derecho son múltiples. Mencionarlos y describirlos le llevaron tres gruesos volúmenes a Antonio Hernández-Gil (Metodología de las Ciencias del Derecho, segunda edición, Madrid, España). Ellos registran diferencias sustanciales entre sí y, en consecuencia, también difieren las conclusiones obtenidas por quienes los aplican.

Los juristas comprenden el significado de los métodos en el proceso de adquisición de conocimientos bajo la pretensión de que dichos conocimientos sean considerados científicos.

El método de adquisición de conocimientos científicos debe adecuarse a la índole del objeto a conocer. Así un objeto empírico -como una tormenta tropical- que se da en el espacio y en el tiempo es cognoscible científicamente mediante el empleo de un método empírico. Un objeto ideal, como una relación lógica, o una proposición matemática o una serie numérica es cognoscible mediante el empleo de un método racional. Un objeto cultural como una pintura o una sinfonía o una acción humana en curso de desarrollo es cognoscible por la comprensión de su sentido. Así, tres clases diferentes de objetos susceptibles de ser conocidos (los objetos naturales, los objetos ideales, los objetos culturales) sólo pueden ser conocidos científicamente por métodos acordes con las características propias del objeto a conocer.

En el caso del conocimiento llamado conocimiento científico del Derecho, el método a utilizar por el sujeto cognoscente debe ser un método adecuado a las características del Derecho, objeto a conocer. Sin embargo, como se sabe, no se ha logrado entre los juristas una coincidencia satisfactoria acerca de la índole esencial del objeto de su preocupación teorética.

En la Historia de la Ciencia del Derecho se encuentran diversas concepciones filosóficas acerca del objeto Derecho. Para el jusnaturalismo, el De- 
recho es Justicia, un valor; para el racionalismo dogmático, el Derecho es norma, un objeto racional; para el realismo jurídico, el Derecho es comportamiento humano, un objeto cultural.

Se está ante tres clases de objetos. En la medida en que el método de conocimiento se adecue a las características esenciales de los objetos, los métodos serán intuitivos, racionales o empírico respectivamente. Como subsisten diferencias sustanciales acerca de la naturaleza del Derecho como objeto, según se ha visto, subsisten igualmente diferencias acerca de la característica de los diversos métodos jurídicos.

\section{Los métodos, los jueces y los abogados}

Los jueces se encuentran frente al litigio sometido a su consideración para poner fin a la disputa mediante la aplicación del Derecho. A este efecto cuentan con los diversos métodos de interpretación del Derecho desarrollados a lo largo de la historia del Derecho. Estos métodos pueden llevar a resultados similares o, lo que es más común, pueden llevar a diferentes resultados. Si ello es así, como lo muestra la experiencia cotidiana de los Tribunales, surge el delicado problema de la selección del método interpretativo a aplicar para la resolución de la controversia. Si los métodos llevan a diferentes resultados, el juez no sólo enfrenta la dificultad de identificar el Derecho aplicable. Debe, además, elegir el método de interpretación a aplicar en el caso.

La historia de la Ciencia del Derecho pone de manifiesto dos aspectos de la máxima importancia en esta materia: Primero: no existe una jerarquía de métodos interpretativos, de manera tal que pueda sostenerse una cierta prioridad en la aplicación de un determinado método. Segundo: no existe un método para la elección de un método. El juez se encuentra, por lo tanto, frente a una doble selección, la del Derecho aplicable y la del método interpretativo.

El positivismo exegético francés que surgió con la redacción y la aplicación del Código Napoleón afirmó la prioridad de un método gramatical de interpretación del Derecho. Se identificó al Derecho con la ley sancionada por los representantes del pueblo. La ley era una norma general, expresada mediante palabras del lenguaje natural. Cuando éstas eran claras, el Juez debía atenerse al significado gramatical de las mismas. Los legisladores habían hablado y los jueces debían atenerse a sus palabras. Ello concordaba con la ideología que inspiró la Revolución francesa. El pueblo era soberano pero se manifestaba a través de sus representantes. Conocer el derecho era conocer las palabras pronunciadas por los representantes del pueblo. Cuando esas palabras eran claras ahí terminaba el proceso interpretativo de los jueces. El método interpretativo era gramatical. Traducía una cen- 
tenaria tradición cuyo origen se remontaba a los glosadores y post-glosadores en épocas medievales.

La historia de las Ciencias del Derecho puso de manifiesto el corto alcance del método interpretativo gramatical. Por lo pronto, las palabras del lenguaje natural son ambiguas, i.e. acreditan diversos significados. Basta abrir un diccionario para comprenderlo. Pero, además, las palabras son vagas. Ellas exhiben un núcleo de clara significación, rodeado de un halo de incertidumbre significativa. La palabra «automóvil» alude con cierta claridad a un vehículo autopropulsado por un motor a explosión guiado por un sistema de conducción cuyo desplazamiento se apoya en cuatro ruedas, equipado con asientos para un conductor y pasajeros. ¿Y si el vehículo sólo tiene tres ruedas? ¿Procede llamarlo automóvil?

Las palabras son «claras» cuando los objetos mencionados por ellas son claros, pero cuando estos objetos acusan modificaciones, alteraciones, mutaciones, es decir, cuando es la realidad la que pierde claridad como consecuencia del cambio, entonces las palabras que antes eran claras, dejan de serlo.

Como el Derecho es un objeto cultural histórico el cambio es inevitable. De ello tenemos conciencia porque así se lo intuye de una manera constante en nuestra existencia cotidiana. En consecuencia, palabras que eran «claras» antes del cambio, se transforman en palabras ambiguas o vagas, cuando el cambio se produce.

En la concepción clásica de la Escuela francesa de la exégesis, si las palabras del legislador no eran claras, correspondía averiguar lo querido por el Legislador. Tal averiguación constituía un proceso de índole histórico. Los legisladores eran hombres racionales, inspirados por ciertas aspiraciones, dedicados a la tarea de lograr ciertos objetivos. Las leyes por ellos sancionadas eran el producto de una actividad creadora, dedicada a la consecución de determinadas finalidades. Por lo tanto, frente a palabras ambiguas o vagas pronunciadas por los legisladores en el acto de legislar, debía atribuirse a las palabras vagas o ambiguas aquel significado que fuera consistente con las motivaciones o razones de los legisladores. Buscar la intención de los legisladores ampliaba considerablemente el campo de la investigación: le daba a jueces y abogados y juristas una amplia gama de posibilidades interpretativas. En efecto, eran múltiples, los motivos que alentaban a los legisladores, quienes, por otro lado, también acreditaban diferencias entre ellos mismos. Por otro lado, los legisladores participaban, con su actividad legislativa, de un largo proceso histórico en el que se identificaban diversas tendencias, objetivos, creencias y diferencias. No se estaba ante un proceso lineal de amplia consistencia lógica, sino de ajustes y cambios de diverso grado de intensidad y duración. 
Este método exegético, pues, colocaba en manos de los jueces y abogados múltiples posibilidades interpretativas. Las ricas y reiteradas modificaciones de la realidad en que actuaban los unos y los otros suministraban a los intérpretes diversas posibilidades metódicas.

Fuertes núcleos del pensamiento jurídico alemán se inclinaron a seguir un camino diferente cuando se encontraron frente al obstáculo consistente en la ambigüedad y la vaguedad de las palabras utilizadas para enunciar normas jurídicas generales.

Bajo la inspiración de Savigny y teniendo a la vista el ciclo histórico consumado del Derecho Romano, la doctrina alemana creyó posible extraer de ese objeto histórico conceptos jurídicos capaces de trascender su carácter mutable y finito para transformarse en un sistema lógico que pudiera suministrar el conjunto de las significaciones abstractas generales (las definiciones, las «naturalezas jurídicas», los conceptos esenciales) con ayuda de las cuales se podían eliminar las contradicciones, y las divergencias, que se pudieran encontrar en el sistema jurídico nacional. Formuladas por los juristas alemanes las definiciones básicas (por ejemplo personas, acto jurídico, capacidad, posesión, propiedad, usufructo, uso, compraventa, mandato, sociedad, arrendamiento, cesión de derechos, compensación, prescripción, privilegio, sucesión, transmisión inter vivos, transmisión mortis causa, etc.), se procedía a su clasificación conforme a ciertas ideas. Se constituía así una Ciencia normativa del Derecho cuyos enunciados hacían posible disolver las contradicciones y eliminar las «lagunas» aparentes del sistema jurídico. El Derecho se presentaba como un todo, coherente y completo. A partir de las definiciones, las «naturalezas jurídicas», y las teorías era posible desarrollar por vía deductiva conclusiones aplicables en el tratamiento y la resolución de conflictos. El Derecho ganaba así un elevado grado de cohesión y consistencia que eliminaba divergencias, y permitía afianzar el orden en el seno del grupo social.

Por este excepcional grado de coherencia el pueblo alemán debió pagar un precio, en términos de sentencias duras, implacables, ajenas a las múltiples peculiaridades de cada caso. Ya lo admitió el viejo Thering cuando decidió abandonar el mundo de los conceptos para descender al mundo de los intereses, y cuando adoptó una concepción teleológica para hacer del Derecho un instrumento que permitiera alcanzar objetivos valiosos.

\section{La selección del derecho y la selección de los métodos interpretativos}

La experiencia cotidiana en los Tribunales, en las entidades civiles, comerciales, económicas, en las asociaciones culturales, religiosas, en las instituciones políticas, pone de manifiesto la posibilidad de aplicar diversas normas legales, jurisprudenciales y consuetudinarias y de seguir más de una 
doctrina, de modo tal que se hace necesario seleccionar algunas normas para lograr un determinado resultado, dejando de lado otras normas jurídicas, igualmente aplicables al caso, pero que llevan a resultados diferentes.

El pensamiento clásico desarrollaba sus tesis y sus conclusiones porque presuponía que cada norma exhibía un cierto significado y era aplicable a cierta clase de hechos. Recibida la norma aplicable entonces entraba a jugar el método deductivo. De esta manera quedaba oculto y disimulado el momento crucial de la selección de una o más normas jurídicas, dejando de lado otras normas igualmente aplicables, pero que llevaban a conclusiones distintas. La selección de la norma aplicable no era un proceso lógico, sino axiológico.

La lógica ponía al alcance de los operadores del Derecho diversas normas aplicables, pero la lógica no le permitía elegir una determinada norma y relegar las otras a un segundo plano en el que perdieran gravitación en la decisión del caso.

El Juez, arquetipo del sujeto cognoscente como lo destacaba Cossio, elegía la norma que le permitía hacer justicia en el caso. Ello implicaba realizar en medida equilibrada y racional todos los valores jurídicos, el orden, la seguridad, la paz, el poder, la cooperación, la solidaridad y la justicia.

El reconocimiento del fundamento axiológico del proceso selectivo de las normas que habrán de ser aplicadas al caso ha venido ganando aceptación a lo largo de la corriente centuria. Basta mencionar el Derecho natural existencial, la Escuela de la Institución, el pensamiento neo-kantiano (Rawls), el solidarismo y sociologismo de Roscoe Pound, la concepción Egológica desarrollada por Carlos Cossio, y el pensamiento trialista de Goldschmidt, Jerome Hall, y Miguel Reale para mencionar solo algunas de las teorías desplegadas en el curso del presente Siglo.

No ha merecido igual atención, en cambio, el proceso de selección del método interpretativo a aplicar tanto en el plano concreto e individual de un caso sometido a decisión judicial, como en el plano general del Derecho vigente en el seno de la comunidad.

La doctrina ha tendido a ignorar la incidencia del método en el conocimiento del Derecho por haber practicado una suerte de corte entre el objeto a conocer y el sujeto cognoscente. No se comprendió que siempre se accede al objeto desde una cierta posición metódica, como lo habían destacado Husserl y Ortega y Gasset.

La más simple y sencilla lectura de una norma jurídica escrita implica necesariamente la adopción de un método interpretativo, como, por ejemplo, el gramatical. Habitualmente el lector de la norma no gana conocimiento reflexivo de la selección practicada. Aún los jueces y los abogados, no obstante su función y la índole de sus tareas, omiten reflexionar sobre la 
opción metódica al adoptar espontáneamente el método gramatical para conocer la norma jurídica de su interés.

La profunda separación del objeto, por un lado, del sujeto que lo conoce, por el otro lado, deforma el proceso cognoscitivo. Al objeto accede el sujeto cognoscente desde una cierta perspectiva metódica. Esto es ineludiblemente así. Hace a la índole del conocimiento.

La relación cognoscitiva se integra con un sujeto cognoscente, un objeto a conocer y un método cognoscitivo para desvelar o poner de manifiesto el objeto cuyo conocimiento se busca.

Como se señaló más arriba la historia del pensamiento científico acerca del Derecho pone de manifiesto la presencia y la utilización de diversos métodos interpretativos cuya aplicación puede llevar, y habitualmente lleva, a diferentes resultados. El juez, el abogado, el jurista deben elegir, por lo tanto, el método que habrán de aplicar para lograr el conocimiento del Derecho.

Así como los sujetos cognoscentes eligen el Derecho aplicable, igualmente deben elegir el método de interpretación del Derecho. El conocimiento del objeto Derecho implica, por inevitable necesidad, conocerlo mediante la aplicación de un determinado método. El Juez, el abogado, el jurista, pues, habrán de elegir las normas jurídicas aplicables y, simultáneamente, habrán de elegir el método de interpretarlas. Ambas opciones se llevan a cabo en base a la intuición de los valores en juego.

\section{El fundamento axiológico de la selección del método interpretativo}

La utilización de diversos métodos interpretativos en el cumplimiento de sus diversas funciones por parte de los jueces, los abogados y los juristas introduce una instancia axiológica en el proceso de selección de uno o más determinados métodos interpretativos.

Los diversos sujetos cognoscentes mencionados tienen a su disposición diversos procedimientos intelectuales para acceder al objeto de su interés. Pueden elegir libremente uno o varios. Intuyen, sin embargo, que no es indiferente la opción. Métodos diversos llevan a consecuencias diversas.

Como en el caso de la selección de la norma jurídica aplicable el Juez, al dictar sentencia, y los abogados al defender a su cliente y los juristas al delimitar el sentido y alcance de las normas jurídicas generales, se basan en los respectivos valores axiológicos en juego en cada selección metódica.

Domina, ciertamente, la búsqueda de la justicia. El Juez sabe y acepta que su función central es hacer justicia a las partes involucradas en la controversia. Su sentencia constituye una suerte de notificación a la comunidad acerca de la actitud que los jueces, funcionarios del Estado, habrán de tomar cuando surja un conflicto similar. Por lo tanto, la sentencia tiene un alcance mayor que el de dirimir una disputa individual. Pone fin a una con- 
troversia concreta y al así hacerlo sienta, además, un precedente, establece un criterio conforme al cual futuras disputas similares merecerán una misma consideración.

La justicia significa equilibrio, conforme al criterio clásico platónico, es decir, la armonía de todos los valores jurídicos. Impone al Juez el deber de dictar una sentencia que contemple la preservación del orden y la seguridad, el poder y la paz, la cooperación y la solidaridad. El juez es un órgano de la comunidad y, como tal, debe contribuir con su sentencia a la afirmación del orden, es decir, una secuencia regular de los comportamientos y de los acaecimientos naturales que permita a las partes y a la comunidad en su conjunto actuar con eficacia al insertarse los actos en la cadena de los acaecimientos y lograr los objetivos deseados.

Los jueces y las partes están expuestos a los riesgos alojados en el mundo circundante. Lo están igualmente los miembros de la comunidad. La seguridad permite identificar y neutralizar los riesgos que ponen en peligro la integridad de los bienes, tanto los vivientes como los que el hombre crea. Ello permite la previsión de los daños y la subsistencia de la vida. El Juez tiene conciencia del carácter primario y elemental del valor seguridad. No elimina los riesgos, porque ellos son inherentes a la condición humana, pero al preverlos se encuentra en condiciones de minimizar sus efectos dañinos. El Juez con su sentencia se cuidará de no debilitar la seguridad jurídica.

El Juez, órgano de la comunidad, no sólo impone orden haciendo posible la acción eficaz de los hombres y crea condiciones de seguridad para los protagonistas de la vida comunitaria. Además, concurre con su sentencia al mantenimiento de relaciones jerárquicas en el seno de la comunidad de modo tal que ésta reconozca y acepte el ejercicio del poder por un grupo dirigente dotado de la autoridad requerida para fijar objetivos a ser perseguidos por la comunidad en su conjunto. El Juez es parte de esa estructura de poder en cuya preservación y eficacia se encuentra interesado. El debilitamiento de las autoridades públicas afecta de modo directo al Juez pues sus sentencias se apoyan, en última instancia, en la fuerza pública. El Juez debe ser cauteloso en el mantenimiento intacto de sus potestades como órgano de la comunidad, responsable de poner fin a los diferendos surgidos en el seno de la misma.

Mediante el apoyo que suministra un aparato eficiente de autoridad, el Juez debe preocuparse por el establecimiento y desarrollo de vínculos de paz y entendimiento entre los integrantes de la comunidad. La paz es conquistada cuando quienes conviven se identifican como amigos, como personas unidas por el afecto. Los demás son como uno. Son partes de un todo al que pertenecen. Se encuentran unidos por relaciones de hermandad y mutua comprensión. Los fortalece el compartir creencias y vivir en una ge- 
nerosa convivencia de unidad. En un cuadro de estas características la misión del Juez se cumple en un contexto de reconocimiento, aceptación y comprensión. Ello facilita la superación del conflicto y la aceptación de la sentencia sin quebrar los lazos de unidad y fraternidad. El Juez comprende el profundo significado del mantenimiento de la paz, la posibilidad que ella abre para promover el entendimiento, y el sentimiento de hermandad. Sabe que, bajo condiciones de paz, será más fácil superar las tensiones provocadas por pretensiones contrapuestas y superar litigios sin dejar heridas abiertas.

Mediante la acción cooperativa los integrantes de la comunidad multiplican los bienes susceptibles a su disposición. Las limitaciones propias de la acción aislada e independiente pueden ser superadas mediante la acción cooperativa. Se amplía el horizonte de las opciones vitales. El individuo, en vez de sentirse abandonado, incapaz o débil, comienza a comprender el mayor alcance de su acción cuando cuenta con la cooperación de los demás.

Los jueces tienden a promover la cooperación con sus sentencias. Sabedores del carácter multiplicador de la acción cooperativa, evitan sentar precedentes que puedan transformarse en obstáculo de la acción coordinada de los integrantes de la comunidad.

El Juez es claramente consciente de la significación aglutinante y unitaria de la solidaridad. Ella se traduce en la participación en las pérdidas y en las ganancias de la acción de los integrantes de la comunidad. La suerte de los demás es también su suerte y viceversa. La solidaridad liga a todos quienes la practican mediante un vínculo espiritual que lleva a la asunción de una suerte común. Mediante la acción solidaria la vida humana alcanza uno de los más altos niveles de devoción generosa al bienestar de los demás. El individuo es llamado a compartir su destino con el destino de los demás. Los jueces no son ajenos al significado social de la solidaridad y comprenden su gravitación en la administración de la justicia. La solidaridad tiende a la disminución de los conflictos, a la terminación de las disputas y al ajuste racional de las diferencias. Los jueces evitan cualquier clase de acción judicial que pudiera sembrar dudas entre los miembros del grupo social y llevar a la destrucción de los vínculos de la solidaridad.

La justicia que debe guiar la acción del Juez en la selección del método o de los métodos a utilizar en el conocimiento y la decisión del conflicto no es sólo la justicia de la armonía y el equilibrio de todos los valores jurídicos. Es también la justicia racional aristotélica de la igualdad y la proporcionalidad.

La justicia de la igualdad, la justicia conmutativa, es la que corresponde a las relaciones de personas iguales entre sí. La justicia de la proporcionalidad es la correspondiente a las relaciones entre personas que no se en- 
cuentran en un plano de igualdad sino de desigualdad, esto es, la relación entre el ciudadano y el Estado.

La justicia conmutativa requiere la igualación de las partes, la corrección de las deficiencias y desigualdades existentes para colocar a todas las personas en un punto inicial de igualdad. En esta delicada y compleja tarea el Juez juega una función de importancia clave.

La justicia distributiva consiste en la distribución de honores, premios, bienes en proporción a sus relativos méritos. La justicia distributiva es debida por el Estado a sus ciudadanos y, en particular, la justicia es debida por los jueces. Los ciudadanos esperan que el Juez tenga en cuenta lo que se les debe en razón del mérito de sus respectivos comportamientos. Los jueces deben decidir los conflictos de tal manera que cada parte reciba el mejor tratamiento posible que las circunstancias hagan posible. Distribuir conforme a los méritos de cada ciudadano fortalece el entendimiento colectivo.

Así como el Juez selecciona la norma jurídica aplicable al caso en base a los respectivos méritos axiológicos de las normas que compiten por ser aplicadas en el caso, de la misma manera selecciona el Juez el método interpretativo que habrá de aplicar en el conocimiento y la decisión del caso. Ambos procesos son simultáneos y se implican recíprocamente. Tanto la selección de las normas aplicables como la elección de los métodos interpretativos están guiadas por consideraciones axiológicas. El Juez elegirá aquella norma y aquel método que aseguren la justa decisión del conflicto, es decir, que logre el equilibrio entre todos los valores jurídicos y establezca igualdad entre los iguales y proporcionalidad en la distribución de los bienes según los méritos de los actores. 
DOXA 21-II (1998) 